\title{
Short-Term Effects of Humidification Devices on Respiratory Pattern and Arterial Blood Gases During Noninvasive Ventilation
}

\author{
François Lellouche MD PhD, Claudia Pignataro MD, \\ Salvatore Maurizio Maggiore MD PhD, Emmanuelle Girou PharmD PhD, \\ Nicolas Deye MD MSc, Solenne Taillé Eng, \\ Marc Fischler MD, and Laurent Brochard MD
}

\begin{abstract}
BACKGROUND: The impact of humidification devices on ventilatory and arterial blood gases parameters during noninvasive ventilation (NIV) remains controversial. The aim of the study was to compare the short-term impact of heat and moisture exchangers (HMEs) and heated humidifiers (HHs) during NIV for either hypercapnic or hypoxemic acute respiratory failure. METHODS: Consecutive subjects receiving NIV were successively treated with HME and HH in randomized order for $30 \mathrm{~min}$ each. At the end of each period, arterial blood gases were measured and ventilatory parameters were recorded. RESULTS: Eighty-one subjects were enrolled, of whom 52 were hypercapnic (with or without acidosis) and 29 hypoxemic. Minute ventilation was greater with the HME, in comparison with the HH (15 [12-18] vs 12 [10-16] median [interquartile range], $P<.001)$, while $\mathrm{P}_{\mathrm{aCO}}$ was increased when using $\mathrm{HME}$, indicating a dead space effect. This effect was observed in all subjects, but was more pronounced in hypercapnic subjects $\left(\mathrm{P}_{\mathrm{aCO}_{2}} 62 \pm 17 \mathrm{~mm} \mathrm{Hg}\right.$ with $\mathrm{HME}$ vs $57 \pm 14$ with $\mathrm{HH}, P<.001)$. In a subgroup of 19 subjects with respiratory acidosis, alveolar hypoventilation improved only with the HH. The amplitude of the dead space impact was a function of the degree of hypercapnia. CONCLUSIONS: Use of an $\mathrm{HME}$ decreased $\mathrm{CO}_{2}$ elimination during NIV, despite increased minute ventilation, especially in hypercapnic subjects. Key words: noninvasive ventilation; humidification; heated humidifiers; heat and moisture exchangers; dead space; alveolar hypoventilation; acute respiratory failure; COPD. [Respir Care 2012;57(11):1879-1886. (C) 2012 Daedalus Enterprises]
\end{abstract}

\begin{abstract}
Drs Lellouche, Pignataro, Taillé, Fischler, and Brochard are affiliated with the Service de Réanimation Médicale, Assistance Publique Hôpitaux de Paris, Centre Hospitalier Albert Chenevier-Henri Mondor, Créteil, France. Drs Lellouche, Maggiore, and Brochard are affiliated with the Institut National de la Santé et de la Recherche Médicale Unit 955, Equipe 13, Créteil, France. Dr Girou is affiliated with the Unité de Contrôle, Epidémiologie et Prévention de l'Infection, Assistance Publique Hôpitaux de Paris, Hôpital Henri Mondor, Créteil, France. Dr Deye is affiliated with the Service de Réanimation Médicale, Hôpital Lariboisière, Paris, France. Dr Lellouche is also affiliated with Service de Soins Intensifs de Chirurgie Cardiaque, Centre de Recherche Institut Universitaire de Cardiologie et de Pneumologie de Québec, Université Laval, Quebec City, Quebec, Canada. Dr Pignataro is also affiliated with the Departement d'Anesthesie et Réanimation, Hopital Lariboisière, Paris, France. Dr Maggiore is also affiliated with the Istituto di Anestesiologia e Rianimazione, Università Cattolica Policlinico A Gemelli. Rome, Italy. Dr Brochard is also affiliated with the Université Paris 12, Créteil, France.
\end{abstract}

\begin{abstract}
Dr Lellouche presented a version of this paper at the International Conference of the American Thoracic Society, held May 17-22, 2002, in Atlanta, Georgia.

The humidifiers for this study were supplied free of charge by Fisher \& Paykel, which was not involved in the design or conduct of the study, collection, management, analysis, or interpretation of the data; or preparation, review, or approval of the manuscript.

Dr Brochard has disclosed relationships with Hudson and Fisher \& Paykel.

Correspondence: François Lellouche MD PhD, Unité de Soins Intensifs de Chirurgie Cardiaque, Groupe de Recherche en Santé Respiratoire, Centre de Recherche de l'Institut Universitaire de Cardiologie et de Pneumologie de Québec, 2725 Chemin Sainte-Foy, Ville de Québec, Québec Canada G1V 4G5. E-mail: francois.lellouche@criucpq.ulaval.ca.
\end{abstract}

DOI: $10.4187 /$ respcare. 01278 


\section{Introduction}

Noninvasive ventilation (NIV) delivered via a face mask reduces the need for endotracheal intubation and the subsequent risk of morbidity and mortality. ${ }^{1-3}$ NIV is particularly useful in patients with acute hypercapnic exacerbations of COPD. ${ }^{1,4,5}$ NIV failure, which has been reported in $20-50 \%$ of patients, 6,7 is ascribed to inadequate $\mathrm{CO}_{2}$ removal $^{8-12}$ and poor tolerance of the technique.,7

It is well established that gases delivered through an endotracheal tube must be humidified, because dry inspired gases have deleterious effects. ${ }^{13,14}$ This statement is not so clear during NIV. ${ }^{15}$ However, there are several arguments favoring the use of humidification during NIV. First, the complications related to dry gases application are very frequent during NIV ${ }^{16}$ and may reduce tolerance of this technique. When NIV is delivered using a standard intensive-care ventilator, the upper airways are not bypassed, but receive dry inspired gases. ${ }^{17}$ The upper airways may be unable to humidify these gases adequately, particularly in mouth-breather patients or when high inspiratory flows are used. Another argument is the frequency of bronchial hyper-reactivity among patients requiring NIV, ${ }^{18,19}$ while dry gases are known to aggravate this state ${ }^{20}$ and can be used to measure airway responsiveness equally to methacholine and other cholinergic analogues or histamine. ${ }^{21}$ Two humidifying devices are commonly used with intensive care ventilators: heated humidifier ( $\mathrm{HH}$ ) and heat-and-moisture exchanger (HME). Both devices can adequately humidify inspired gas, even though leaks reduce inspired humidity with $\mathrm{HME} .{ }^{17} \mathrm{HME}$ devices are frequently used because of their simplicity and lower cost. ${ }^{22}$ Since they are placed between the Y-piece and the patient, they add substantial dead space to the circuit, leading to well known dead-space effects during assisted mechanical ventilation, ${ }^{23-25}$ and can also marginally increase the resistance to flow. ${ }^{26}$ The negative impacts of HME dead space during NIV were not found in a recently published study 27 but have been previously demonstrated in 2 previous physiologic studies, including limited number of subjects. ${ }^{28,29}$ Jaber et al found that $\mathrm{HME}$ was associated with significantly reduced $\mathrm{CO}_{2}$ clearance, compared to $\mathrm{HH}$, in spite of increased minute ventilation. ${ }^{28}$ We showed that the $\mathrm{HME}$ device causes a large increase in work of breathing, compared to $\mathrm{HH}$, as well as an increase in minute ventilation. ${ }^{29}$ The number of subjects was too small to demonstrate an impact on arterial blood gases in our previous work. We thus addressed this question through a simple clinical study, with no assessment of subject effort, but including a large number of subjects with all degrees of severity or type of respiratory failure. ${ }^{30}$

\section{QUICK LOOK}

\section{Current knowledge}

Humidification during noninvasive ventilation impacts patient comfort and tolerance, and physical characteristics of these devices can affect minute ventilation requirements.

\section{What this paper contributes to our knowledge}

The use of a heat and moisture exchanger during noninvasive ventilation is associated with reduced carbon dioxide elimination, compared to heated humidification. The effect was more pronounced in patients with hypercapnic respiratory failure, high $\mathrm{P}_{\mathrm{aCO}_{2}}$, low tidal volume, and low PEEP.

\section{Methods}

The study protocol was approved by an independent review board (Comité d'Ethique de la Société de Réanimation de Langue Française). The subjects were given written information on the protocol and signed a consent waiver.

\section{Subjects}

Subjects were recruited in the medical ICU of Henri Mondor hospital over a one-year period. Inclusion criteria were recent dyspnea exacerbation and one of the following: respiratory rate $\geq 25$ breaths $/ \mathrm{min}, \mathrm{P}_{\mathrm{aO}_{2}}<60 \mathrm{~mm} \mathrm{Hg}$ with room air, or arterial $\mathrm{pH}<7.38$. Exclusion criteria were a need for immediate endotracheal intubation, severe hypoxemia $\left(\mathrm{F}_{\mathrm{IO}_{2}} \geq 0.80\right.$ to obtain $\left.\mathrm{S}_{\mathrm{aO}_{2}}>90 \%\right)$, respiratory rate $<12$ breaths/min, pneumothorax, and hemodynamic instability.

\section{Protocol}

Consecutive subjects treated using NIV with pressure support were prospectively recruited. Ventilatory support was provided based on local recommendations. ${ }^{31}$ All subjects were ventilated with an ICU ventilator having inspiratory and expiratory lines. The $\mathrm{HH}$ was placed in the inspiratory line, as recommended by the manufacturer, and the HME was placed at the Y-piece. Each subject sat in a chair or in bed at an angle exceeding $30^{\circ}$, and the size of the interface was selected to fit the subject. Standard oronasal masks with different shapes and sizes were used to ensure a proper fit for each subject and to maximize comfort. No flex-tube was placed between the Y-piece and the mask. Hydrocolloid dressings were used to protect the 


\section{Short-Term EfFects of Humidification Devices}

skin. The subject placed the mask on his or her face before the procedure began, when possible. A head strap was used to hold the mask in place. Strap tension was minimized. The first breaths were made with no expiratory pressure, and an inspiratory pressure not exceeding $8 \mathrm{~cm} \mathrm{H}_{2} \mathrm{O}$. Inspiratory and expiratory pressures were increased in increments not exceeding $2 \mathrm{~cm} \mathrm{H}_{2} \mathrm{O}$. The expiratory pressure was gradually increased to $3 \mathrm{~cm} \mathrm{H}_{2} \mathrm{O}$ in COPD subjects, and to a maximum of $10 \mathrm{~cm} \mathrm{H}_{2} \mathrm{O}$ in hypoxemic subjects. The inspiratory pressure was increased to obtain an expired tidal volume between 7 and $9 \mathrm{~mL} / \mathrm{kg}$, or 6 and $8 \mathrm{~mL} / \mathrm{kg}$ in COPD subjects. Low doses of sedative were given infrequently to agitated subjects. The physician and nurses explained the different periods and setting modifications to reassure the subjects.

An HME (Hygrobac, DAR, Mirandola, Italy) and an HH (MR850, Fisher \& Paykel Healthcare, Auckland, New Zealand) with heated circuits were compared with a crossover design. HME dead space was $95 \mathrm{~mL},{ }^{32}$ while HME resistance, measured in a previous paper, were equivalent to $\mathrm{HH}$ inspiratory circuit resistances. ${ }^{29}$

We a priori separated 3 groups of subjects:

- Subjects with hypercapnia and respiratory acidosis (usually corresponding to the initiation of NIV treatment)

- Subjects with hypercapnia and without respiratory acidosis (usually corresponding to the stabilization of NIV treatment)

\section{- Hypoxemic non-hypercapnic subjects}

Hypercapnia was defined as a $\mathrm{P}_{\mathrm{aCO}}$ exceeding $42 \mathrm{~mm} \mathrm{Hg}$. Acidosis was defined as a $\mathrm{pH}<7.38$. Hypoxemia was defined as a $\mathrm{S}_{\mathrm{pO}_{2}}<90 \%$ when breathing room air. Subjects were ventilated for 30 min with an $\mathrm{HH}$ device and for 30 min with an HME device. The sequence of the humidification device was randomized. At the end of each period (during the 5 last minutes), the ventilatory parameters were recorded from the ventilator (respiratory rate and minute ventilation), and arterial blood gases were measured. The ventilatory settings were selected by the attending physician, and no changes occurred during the whole study time for these settings.

Arterial blood gas measurements were also available for 19 subjects in the respiratory acidosis group at baseline, immediately before the initiation of NIV.

\section{Statistical Analysis}

The primary outcome was the impact of humidification device on physiological parameters (arterial blood gases and breathing pattern). Descriptive statistics, including means, standard deviations, medians, and interquartile ranges, were used to summarize the data. Categorical variables were compared using the Mann-Whitney 2-sample
Table 1. Influence of the HME and HH Devices on Arterial Blood Gases and Respiratory Parameters of All Patients

\begin{tabular}{|c|c|c|c|}
\hline & $\begin{array}{c}\text { HME } \\
(n=81)\end{array}$ & $\begin{array}{c}\mathrm{HH} \\
(n=81)\end{array}$ & $P^{*}$ \\
\hline $\mathrm{pH}$ & $7.38(7.32-7.43)$ & $7.40(7.35-7.45)$ & $<.001$ \\
\hline $\mathrm{P}_{\mathrm{aCO}_{2}}, \mathrm{~mm} \mathrm{Hg}$ & $47(40-58)$ & $46(39-56)$ & $<.001$ \\
\hline $\mathrm{P}_{\mathrm{aO}_{2}}, \mathrm{~mm} \mathrm{Hg}$ & $86(73-106)$ & $84(71-102)$ & .45 \\
\hline $\begin{array}{l}\text { Respiratory rate, } \\
\text { cycles/min }\end{array}$ & $27(23-33)$ & $24(20-30)$ & $<.001$ \\
\hline $\begin{array}{l}\text { Expired tidal volume, } \\
\mathrm{mL}\end{array}$ & 535 (456-638) & $545(453-667)$ & .89 \\
\hline $\begin{array}{l}\text { Minute ventilation, } \\
\mathrm{L} / \mathrm{min}\end{array}$ & $15(12-18)$ & $12(10-16)$ & $<.00$ \\
\hline \multicolumn{4}{|c|}{$\begin{array}{l}\text { Results are expressed as median (interquartile range). } \\
\text { * Statistical test used for comparison: Wilcoxon matched-pairs signed-rank test (nonparametric } \\
\text { test). } \\
\text { HME = heat and moisture exchanger } \\
\mathrm{HH}=\text { heated humidifier }\end{array}$} \\
\hline
\end{tabular}

rank sum test. Continuous variables were compared using the Spearman rank correlation. Continuous variables were not dichotomized, except PEEP level. We tested the carryover effect to determine the impact of the sequence order (first NIV period with HH or with HME) and the impact of the period (first vs second NIV period). We analyzed the association between the $\Delta \mathrm{P}_{\mathrm{aCO}_{2}}$ between the 2 humidification systems and $\mathrm{P}_{\mathrm{aCO}}$ under the $\mathrm{HME}$ with univariate analysis. We then used multiple linear regression to identify variables that made an important contribution to the variability of $\Delta \mathrm{P}_{\mathrm{aCO}_{2}}$, to adjust for possible confounding variables. Despite being significant in the univariate analysis, the type of respiratory failure was not entered in the multiple regression model, due to its close relationship with the variable $\mathrm{P}_{\mathrm{aCO}}$ under HME. The model was checked for normality, linearity, homoscedasticity, and multicollinearity. Statistical analysis was performed using statistics software (Stata 8.2, StataCorp, College Station, Texas). A $P$ value $<.05$ was considered significant.

\section{Results}

Eighty-one subjects were included in our study. The indications for NIV were acute hypoxemic respiratory distress (from unilateral pneumonia or ARDS) in 26 subjects, exacerbation of COPD in 28, post-extubation respiratory distress in 7, cardiopulmonary edema in 12 , and other indications in 8 . The sex ratio $(\mathrm{M} / \mathrm{F})$ was $54 / 27$, the mean age was $63 \pm 14$ years, and the mean Simplified Acute Physiology Score II score was $41 \pm 28$. Ventilatory settings were as follows: the pressure support level was $14 \pm 3 \mathrm{~cm} \mathrm{H}_{2} \mathrm{O}$, PEEP was set at $5 \pm 2 \mathrm{~cm} \mathrm{H}_{2} \mathrm{O}$, and $\mathrm{F}_{\mathrm{IO}_{2}}$ was $0.51 \pm 0.23$.

Table 1 and Figure 1 present the impact of the humid- 


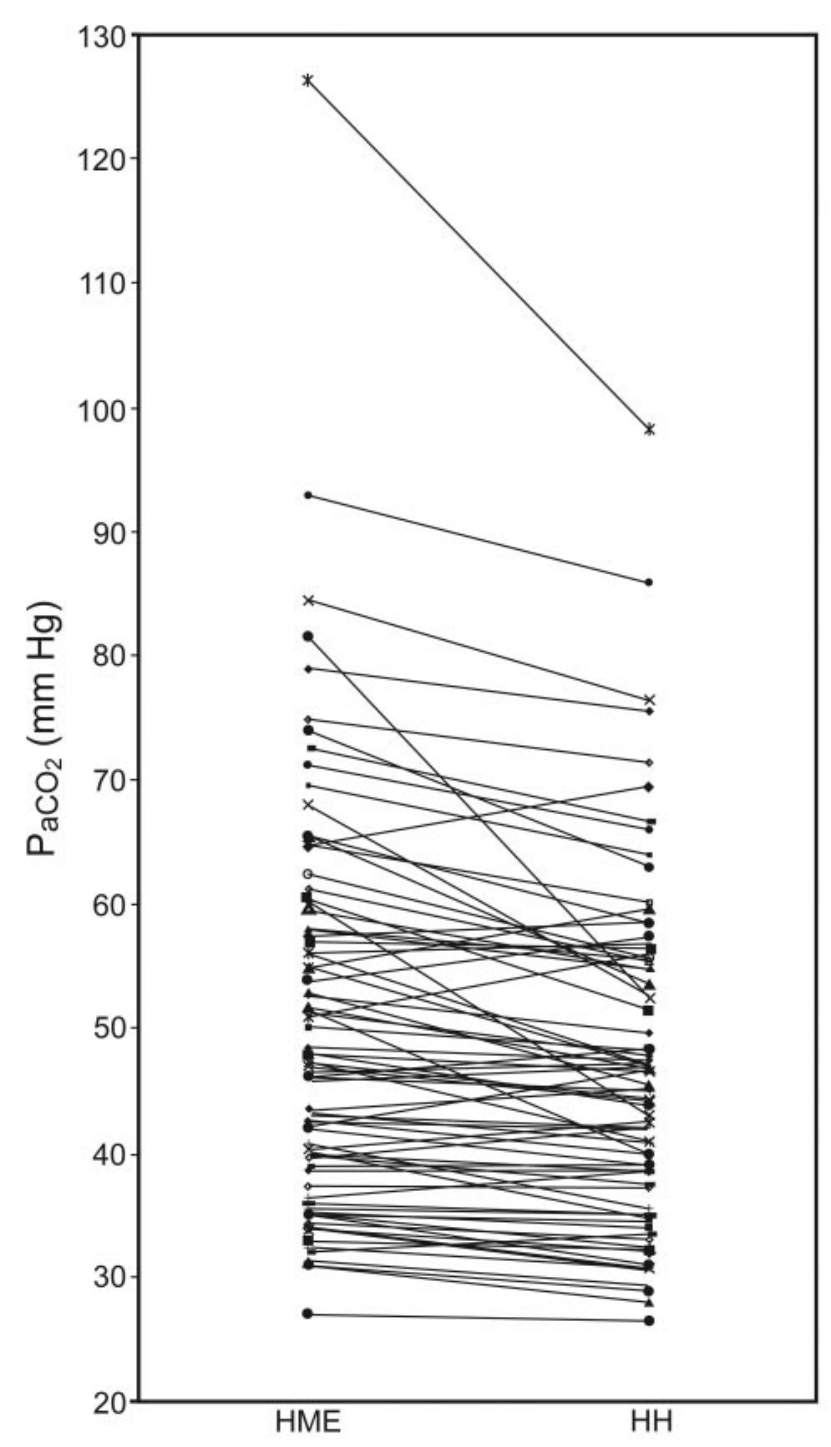

Fig. 1. Comparison of the $\mathrm{P}_{\mathrm{aCO}}$ at the end of each study period: heat and moisture exchanger ( $\mathrm{HME}$ ) versus heated humidifier $(\mathrm{HH})$ in the entire study population. $\mathrm{P}_{\mathrm{aCO}_{2}}$ was significantly higher with the HME than with the $\mathrm{HH}(51 \pm 17 \mathrm{~mm} \mathrm{Hg}$ vs $47 \pm 13 \mathrm{~mm} \mathrm{Hg}$, $P<.001)$.

ification devices on arterial blood gases and respiratory parameters for the whole population. The results for the different populations (hypercapnia with or without acidosis and hypoxemia) are presented in Table 2.

In all groups, the HME led to small but significant increase in $\mathrm{P}_{\mathrm{aCO}}$, despite significantly higher minute ventilation (see Table 2). These effects were more pronounced in hypercapnic subjects (see Table 3 and Fig. 2). Baseline arterial blood gases prior to NIV were available for 19 subjects with respiratory acidosis. $\mathrm{CO}_{2}$ removal improved over baseline only with the HH device, and not with the HME. Figure 3 shows the evolution of $\mathrm{P}_{\mathrm{aCO}}$ according to the device used in these subjects.
The evaluation of a carry-over effect demonstrated that there is a period effect (first vs second), as expected due to the impact of NIV $(P=.010)$, but no sequence effect $(P=.70)$, indicating that beginning with $\mathrm{HH}$ or HME did not have any effect on the results for $\mathrm{P}_{\mathrm{aCO}}$ variations.

In univariate analysis, the most influential factors on the difference in $\mathrm{P}_{\mathrm{aCO}}$ between the 2 humidification systems $\left(\mathrm{P}_{\mathrm{aCO}}\right.$ with $\mathrm{HME}-\mathrm{P}_{\mathrm{aCO}}$ with $\left.\mathrm{HH}\right)$ were the presence of hypercapnic respiratory failure, the level of initial $\mathrm{P}_{\mathrm{aCO}_{2}}$, and the expired tidal volume (see Table 3). Multiple regression analysis showed that $\mathrm{P}_{\mathrm{aCO}}$ level under $\mathrm{HME}$ was the best significant predictor of $\Delta \mathrm{P}_{\mathrm{aCO}_{2}}$ after adjustment for PEEP level, expired tidal volume, and $\mathrm{pH}$ (Table 4).

\section{Discussion}

The present study assessed the effect of the main humidification devices on breathing pattern and arterial blood gases in a large number of consecutive subjects with various indications for NIV. The HME had a negative impact on $\mathrm{CO}_{2}$ elimination, compared to the $\mathrm{HH}$ (see Table 1). $\mathrm{CO}_{2}$ removal was reduced in all subject groups (see Tables 2 and 3), despite increased minute ventilation triggered by the added dead space of the HME. The effects were more pronounced in subjects with hypercapnic respiratory failure, high $\mathrm{P}_{\mathrm{aCO}}$, low tidal volume, and low PEEP (see Table 3).

Few data are available on humidification during NIV, and very few studies in the literature can be compared to the present study. Our group previously conducted a physiologic study comparing $\mathrm{HH}$ and HME devices during NIV in hypercapnic subjects. ${ }^{29}$ It showed that there is a significant increase in work of breathing, combined with an increase in minute ventilation, with the HME. However, a number of limitations due to experimental conditions made it impossible to evaluate the effect of the humidification devices on arterial blood gases in the previous study. First, the added dead space due to the pneumotachograph (almost $30 \mathrm{~mL}$ ) may have reduced the difference in the volume of dead space of the devices studied. Second, the transdiaphragmatic pressure measurements using a double balloon eso-gastric catheter required patient cooperation. Because of this, patients with high $\mathrm{P}_{\mathrm{aCO}}$ and encephalopathy were excluded from the previous study. Patients were included after a mean ICU stay of 48 hours, and by then most of them had almost recovered from acidosis. ${ }^{29}$

In the present study the experimental conditions were similar to real-life clinical conditions, with no interventions except for changing the humidification device after $30 \mathrm{~min}$. This large subject population made it possible to detect the deleterious effect of dead space on minute ventilation and breathing pattern in different categories of subjects (see Table 2). 


\section{Short-Term EfFects of Humidification Devices}

Table 2. Influence of Humidification Device on Arterial Blood Gases and Ventilator Parameters in Patients With Hypercapnia and Acidosis (Early NIV), Hypercapnia (End of NIV), and in Patients With Hypoxemia

\begin{tabular}{|c|c|c|c|c|c|c|}
\hline & \multicolumn{2}{|c|}{$\begin{array}{l}\text { Hypercapnia With Acidosis } \\
\qquad(n=35)\end{array}$} & \multicolumn{2}{|c|}{$\begin{array}{l}\text { Hypercapnia Without Acidosis } \\
\qquad(n=17)\end{array}$} & \multicolumn{2}{|c|}{$\begin{array}{l}\text { Hypoxemia } \\
(n=29)\end{array}$} \\
\hline & HME & $\mathrm{HH}$ & HME & $\mathrm{HH}$ & HME & $\mathrm{HH}$ \\
\hline $\mathrm{pH}$ & $7.31(7.28-7.34)$ & $7.34(7.30-7.36)^{*}$ & $7.41(7.39-7.44)$ & $7.42(7.40-7.46)^{*}$ & $7.43(7.38-7.45)$ & $7.44(7.41-7.47)^{*}$ \\
\hline $\mathrm{P}_{\mathrm{aCO}_{2}}, \mathrm{~mm} \mathrm{Hg}$ & $60(52-70)$ & $56(47-64)^{*}$ & $50(47-55)$ & $48(45-53)^{*}$ & $36(34-40)$ & $35(32-39)^{*}$ \\
\hline $\mathrm{P}_{\mathrm{aO}_{2}}, \mathrm{~mm} \mathrm{Hg}$ & $85(72-104)$ & $79(70-102)$ & 80 (66-97) & $75(68-96)$ & $92(77-116)$ & $92(76-109)$ \\
\hline f, breaths/min & $27(22-33)$ & $22(18-28)^{*}$ & $23(18-28)$ & $20(18-26)^{*}$ & $30(26-34)$ & $29(24-32) \dagger$ \\
\hline $\mathrm{V}_{\mathrm{T}}, \mathrm{mL}$ & $497(437-584)$ & $509(438-585)$ & $571(517-696)$ & $667(500-737)$ & $611(484-692)$ & $585(454-668)$ \\
\hline$\dot{\mathrm{V}}_{\mathrm{E}}, \mathrm{L} / \mathrm{min}$ & $13.8(11.1-15.1)$ & $11.4(9.4-12.1)^{*}$ & $15.1(11.5-17.0)$ & $12.2(10.0-16.0)^{*}$ & $17.3(14.5-23.0)$ & $16.3(11.7-19.8)^{*}$ \\
\hline \multicolumn{7}{|c|}{ 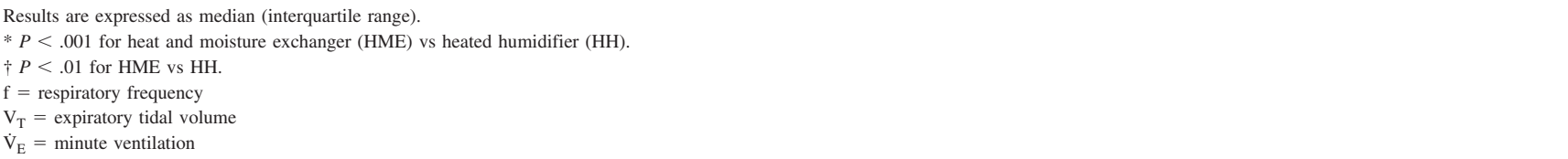 } \\
\hline
\end{tabular}

Table 3. Factors Influencing the $\Delta \mathrm{P}_{\mathrm{aCO}}{ }^{*}$

\begin{tabular}{|c|c|c|}
\hline & $\Delta \mathrm{P}_{\mathrm{aCO}_{2}}$ & $P$ \\
\hline \multicolumn{3}{|l|}{ Type of Respiratory Failure } \\
\hline Hypercapnic & $3.4(1.0$ to 7.0$)$ & .005 \\
\hline Hypoxemic & $1.4(0.4$ to 2.5$)$ & \\
\hline $\mathrm{P}_{\mathrm{aCO}_{2}}, \mathrm{~mm} \mathrm{Hg} \dagger$ & Rho $=0.53$ & $<.001$ \\
\hline $\mathrm{pH}^{\dagger}$ & Rho $=-0.41$ & .001 \\
\hline Expired tidal volume, $\mathrm{mL} \dagger$ & Rho $=-0.28$ & .01 \\
\hline \multicolumn{3}{|l|}{ PEEP, $\mathrm{cm} \mathrm{H}_{2} \mathrm{O}$} \\
\hline $0-5$ & $2.8(1.0$ to 5.9$)$ & .02 \\
\hline $6-10$ & 0.8 (-1.1 to 3.5$)$ & \\
\hline Minute ventilation, $\mathrm{L} / \min \dagger$ & Rho $=-0.16$ & .15 \\
\hline Respiratory rate, cycles $/ \mathrm{min} \dagger$ & Rho $=0.11$ & .36 \\
\hline \multicolumn{3}{|c|}{$\begin{array}{l}\text { Results are expressed as median (interquartile range). Statistical test used for comparison of } \\
\text { continuous variables: Spearman rank correlation. Statistical test used for comparison of } \\
\text { categorical variables: Mann-Whitney 2-sample rank sum test. } \\
* \Delta \mathrm{P}_{\mathrm{aCO}}=\mathrm{P}_{\mathrm{aCO}} \text { with } \mathrm{HME}-\mathrm{P}_{\mathrm{aCO}_{2}} \text { with } \mathrm{HH} . \\
\dagger \mathrm{Level} \text { with } \mathrm{HME} \text {. } \\
\mathrm{HME}=\text { heat and moisture exchanger } \\
\mathrm{HH}=\text { heated humidifier }\end{array}$} \\
\hline
\end{tabular}

In the group of subjects on NIV for decompensation of chronic respiratory failure (respiratory acidosis), there was a marked difference in median minute ventilation between the $\mathrm{HH}$ and HME devices $(11.4 \mathrm{~L} / \mathrm{min}$ vs $13.8 \mathrm{~L} / \mathrm{min}$, $P<.001)$, respiratory rate, and $\mathrm{P}_{\mathrm{aCO}}$. The deleterious effect of dead space in this category of subject was present in the group of subjects with acidosis, corresponding to the initiation of NIV, as well as in the group without acidosis, corresponding to the end of NIV. Jaber et $\mathrm{al}^{28}$ reported the same HME dead-space effect in less severe hypercapnic patients. In their study, most of the patients had no acidosis and hypercapnia was moderate $\left(\mathrm{P}_{\mathrm{aCO}_{2}}\right.$ $46.0 \pm 10.2 \mathrm{~mm} \mathrm{Hg}$ at baseline). ${ }^{28}$

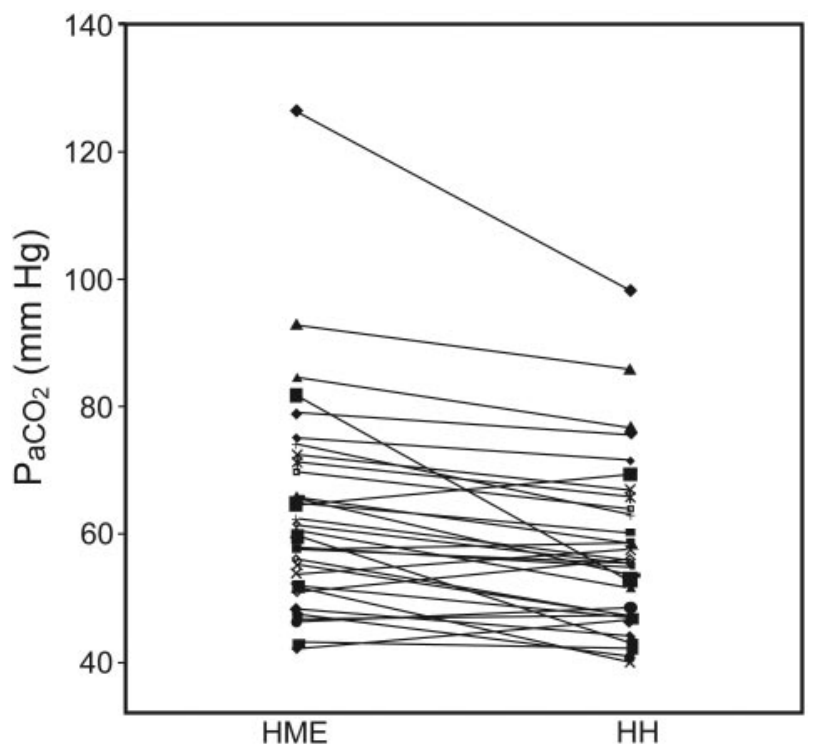

Fig. 2. Comparison of the $\mathrm{P}_{\mathrm{aCO}}$ at the end of each study period: heat and moisture exchanger ( $\mathrm{HME}$ ) versus heated humidifier $(\mathrm{HH})$ in hypercapnic subjects. $\mathrm{P}_{\mathrm{aCO}}$ was significantly higher with the HME than with the $\mathrm{HH}(62 \pm 17 \mathrm{~mm} \mathrm{Hg}$ vs $57 \pm 14 \mathrm{~mm} \mathrm{Hg}$, $P<.001)$.

More striking was the finding that using the HME device for 30 min with NIV impeded $\mathrm{pH}$ correction in the group of subjects with respiratory acidosis, compared to baseline values (before NIV), while $\mathrm{pH}$ levels significantly increased with the $\mathrm{HH}$ device. Interestingly, many studies have reported that a decrease in $\mathrm{CO}_{2}$ during NIV is a strong predictor of success. ${ }^{8-12}$ The effect of HME in subjects treated for hypoxemic respiratory failure was less pronounced. These results are in agreement with those of Jaber et al. ${ }^{28}$ 


\section{Short-Term EfFects of Humidification Devices}

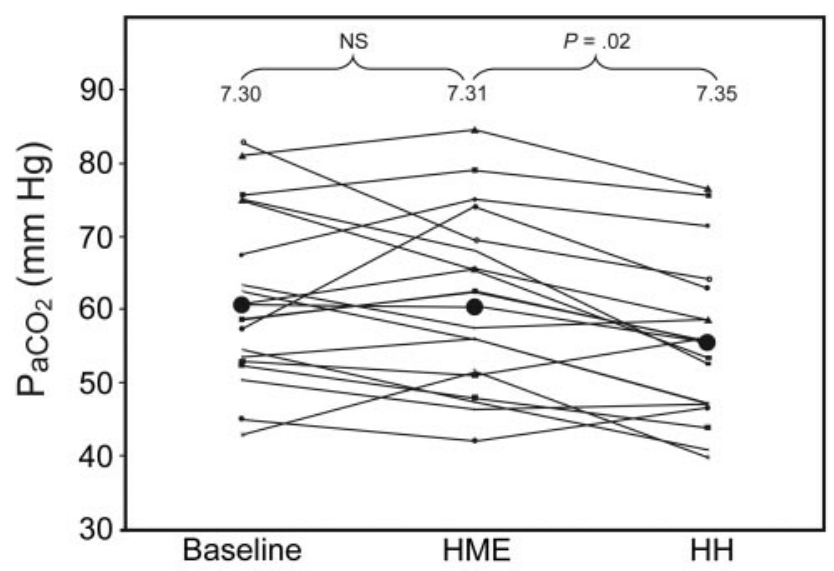

Fig. 3. Influence of the heat and moisture exchanger (HME) and heated humidifier $(\mathrm{HH})$ devices on the $\mathrm{pH}$ correction in hypercapnic subjects with acidosis $(n=19)$; comparison with baseline values before NIV initiation.

Table 4. Multiple Linear Regression Model for $\Delta \mathrm{P}_{\mathrm{aCO}}$

\begin{tabular}{lcc}
\hline \hline \multicolumn{1}{c}{ Independent Variable } & $\beta(95 \% \mathrm{CI})$ & $P$ \\
\hline $\mathrm{P}_{\mathrm{aCO}}{ }^{*}$ & $0.15(0.07$ to 0.24$)$ & .001 \\
PEEP level & $-0.91(-3.28$ to 1.47$)$ & .45 \\
Expiratory tidal volume* & $-0.003(-0.009$ to 0.004$)$ & .40 \\
$\mathrm{pH}^{*}$ & $-6.95(-23.06$ to 9.16$)$ & .39 \\
& & \\
* Level with heat and moisture exchanger. & & \\
$\mathrm{R}^{2}$ for the model $=0.40$. & & \\
\hline
\end{tabular}

Our results were also in agreement with studies on intubated patients. ${ }^{25,33-36}$ With intubated patients on assisted ventilation, HMEs reduce $\mathrm{CO}_{2}$ elimination and increase minute ventilation and work of breathing, compared to HHs. This requires an increase in pressure support from 5 to $8 \mathrm{~cm} \mathrm{H}_{2} \mathrm{O}$, to compensate for the dead space of the HME. ${ }^{25,34,35}$ However, increasing pressure support during NIV is not always feasible because it can increase leaks and patient/ventilator asynchrony. ${ }^{37}$ In the current study the mean pressure support level was already $14 \pm 3 \mathrm{~cm} \mathrm{H}_{2} \mathrm{O}$.

In a recently published study, Boyer et al compared HMEs with small dead space with $\mathrm{HH}$ during NIV and did not find differences in $\mathrm{CO}_{2}$ elimination. ${ }^{27}$ The absence of impact of dead space in this study may be explained by several factors. First, the difference of dead space between HME and HH was small (90 mL vs $33 \mathrm{~mL}$ when flex-tube was used and $38 \mathrm{~mL}$ vs $0 \mathrm{~mL}$ when no flex-tube was used). Also, the pressures used during NIV were very high (around $20 \mathrm{~cm} \mathrm{H}_{2} \mathrm{O}$ of total inspiratory pressure or higher in patients with acute hypoxemic respiratory failure). These high pressures translated to high tidal volumes (around $750 \mathrm{~mL}$ in patients with exacerbation of COPD), which may be difficult to obtain in the real-life setting. Even if there is incontrovertible evidence that dead space impact exists during invasive and noninvasive mechanical ventilation, ${ }^{23-25,29,33-36,38-42}$ it is important to keep in mind that this effect is usually related to the amount of additional dead space. ${ }^{40}$ This impact may have little clinical importance, however, in specific conditions when small dead space HMEs are used. ${ }^{27}$

The effects observed in the present study were related to the dead space and not to the resistance of the humidification devices. Indeed, the inspiratory and expiratory resistance of the HME and $\mathrm{HH}$ devices were similar (2.5 vs $3 \mathrm{~cm} \mathrm{H}_{2} \mathrm{O} / \mathrm{L} / \mathrm{s}$ ), as previously reported. ${ }^{29}$ We used the same devices without flex tubes, as in our previous study. ${ }^{29}$ The physiologic dead space is usually around $150 \mathrm{~mL},{ }^{43}$ while the interface dead space is approximately $70 \mathrm{~mL} \cdot{ }^{44}$ The instrumental dead space of the HME device used in the present study was $95 \mathrm{~mL}$. Instrumental dead space during NIV should be reduced as much as possible, since the aim of NIV is to reduce the work of breathing and to decrease $\mathrm{P}_{\mathrm{aCO}}{ }_{2}{ }^{45}$

In a previous study 29 the HME device reduced the work of breathing but had no effect on minute ventilation when a PEEP of $5 \mathrm{~cm} \mathrm{H}_{2} \mathrm{O}$ was applied. Interestingly, in the

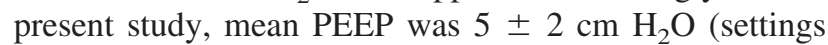
were performed by the attending physician). The negative impact of HME dead space on short-term physiologic parameters such as minute ventilation and arterial blood gases was present within these real-life settings.

The main limitation of the present study was that no conclusions could be reached regarding the impact of the $\mathrm{HH}$ and HME devices on the outcome and efficacy of NIV. However, in patients with marked hypercapnic encephalopathy and clinical signs of increased work of breathing, the dead space should be taken into account and the present results are relevant. An NIV session with a maximal reduction of the dead space should be attempted before proceeding to intubation, although this should not unduly prolong NIV and delay intubation if required. The other limitation of the present study was the absence of a period with no humidification. While this is possible with dedicated NIV turbine-based ventilators, it is not acceptable when using ICU ventilators because of the risk of increased bronchial hyperreacticity with dry gases and dryness of secretions. ${ }^{18-20}$ Another limitation of this study is the short time of the study periods (30 min each), which may have influenced the results.

\section{Conclusions}

In conclusion, the present study revealed that the dead space of the HME device had a short-term negative impact on $\mathrm{CO}_{2}$ elimination and minute ventilation in subjects treated with NIV delivered using an ICU ventilator. This impact was more pronounced in the hypercapnic population. 


\section{Short-Term Effects of Humidification Devices}

\section{REFERENCES}

1. Brochard L, Mancebo J, Wysocki M, Lofaso F, Conti G, Rauss A, et al. Noninvasive ventilation for acute exacerbations of chronic obstructive pulmonary disease. N Engl J Med 1995;333(13):817822.

2. Auriant I, Jallot A, Herve P, Cerrina J, Le Roy Ladurie F, Fournier $\mathrm{JL}$, et al. Noninvasive ventilation reduces mortality in acute respiratory failure following lung resection. Am J Respir Crit Care Med 2001;164(7):1231-1235.

3. Hilbert G, Gruson D, Vargas F, Valentino R, Gbikpi-Benissan G, Dupon M, et al. Noninvasive ventilation in immunosuppressed patients with pulmonary infiltrates, fever, and acute respiratory failure. N Engl J Med 2001;344(7):481-487.

4. Keenan SP, Sinuff T, Cook DJ, Hill NS. Which patients with acute exacerbation of chronic obstructive pulmonary disease benefit from noninvasive positive-pressure ventilation? A systematic review of the literature. Ann Intern Med 2003;138(11):861-870.

5. Plant PK, Owen JL, Elliott MW. Early use of non-invasive ventilation for acute exacerbations of chronic obstructive pulmonary disease on general respiratory wards: a multicentre randomised controlled trial. Lancet 2000;355(9219):1931-1935.

6. Carlucci A, Richard JC, Wysocki M, Lepage E, Brochard L. Noninvasive versus conventional mechanical ventilation. An epidemiologic survey. Am J Respir Crit Care Med 2001;163(4):874-880.

7. Demoule A, Girou E, Richard JC, Taillé S, Brochard L. Increased use of noninvasive ventilation in French intensive care units. Intensive Care Med 2006;32(11):1747-1755

8. Ambrosino N, Foglio K, Rubini F, Clini E, Nava S, Vitacca M. Non-invasive mechanical ventilation in acute respiratory failure due to chronic obstructive pulmonary disease: correlates for success. Thorax 1995;50(7):755-757.

9. Anton A, Guell R, Gomez J, Serrano J, Castellano A, Carrasco JL, et al. Predicting the result of noninvasive ventilation in severe acute exacerbations of patients with chronic airflow limitation. Chest 2000; 117(3):828-833.

10. Poponick JM, Renston JP, Bennett RP, Emerman CL. Use of a ventilatory support system (BiPAP) for acute respiratory failure in the emergency department. Chest 1999;116(1):166-171

11. Putinati S, Ballerin L, Piattella M, Panella GL, Potena A. Is it possible to predict the success of non-invasive positive pressure ventilation in acute respiratory failure due to COPD? Respir Med 2000; 94(10):997-1001.

12. Soo Hoo GW, Santiago S, Williams AJ. Nasal mechanical ventilation for hypercapnic respiratory failure in chronic obstructive pulmonary disease: determinants of success and failure. Crit Care Med 1994;22(8):1253-1261.

13. AARC clinical practice guideline. Humidification during mechanical ventilation. Respir Care 1992;37(8):887-890.

14. Burton JD. Effects of dry anaesthetic gases on the respiratory mucus membrane. Lancet 1962;1(7223):235-238.

15. Branson RD, Gentile MA. Is humidification always necessary during noninvasive ventilation in the hospital? Respir Care 2010;55(2):209216.

16. Nava S, Cirio S, Fanfulla F, Carlucci A, Navarra A, Negri A, et al. Comparison of two humidification systems for long-term noninvasive mechanical ventilation. Eur Respir J 2008;32(2):460-464.

17. Lellouche F, Maggiore SM, Lyazidi A, Deye N, Taille S, Brochard L. Water content of delivered gases during non-invasive ventilation in healthy subjects. Intensive Care Med 2009;35(6):987-995.

18. Cabanes LR, Weber SN, Matran R, Regnard J, Richard MO, Degeorges ME, et al. Bronchial hyperresponsiveness to methacholine in patients with impaired left ventricular function. N Engl J Med 1989; 320(20):1317-1322.
19. Hospers JJ, Postma DS, Rijcken B, Weiss ST, Schouten JP. Histamine airway hyper-responsiveness and mortality from chronic obstructive pulmonary disease: a cohort study. Lancet 2000;356(9238): 1313-1317.

20. Fontanari P, Burnet H, Zattara-Hartmann MC, Jammes Y. Changes in airway resistance induced by nasal inhalation of cold dry, dry, or moist air in normal individuals. J Appl Physiol 1996;81(4):17391743.

21. Cockcroft DW. How best to measure airway responsiveness. Am J Respir Crit Care Med 2001;163(7):1514-1515.

22. Branson R, Davis J, Brown R. Comparison of three humidification techniques during mechanical ventilation: patient selection, cost, and infection considerations. Respir Care 1996;41:809-816.

23. Ranieri VM, Giuliani R, Mascia L, Grasso S, Petruzzelli V, Puntillo $\mathrm{N}$, et al. Patient-ventilator interaction during acute hypercapnia: pressure-support vs proportional-assist ventilation. J Appl Physiol 1996; 81(1):426-436.

24. Iotti GA, Olivei MC, Braschi A. Mechanical effects of heat-moisture exchangers in ventilated patients. Crit Care 1999;3(5):R77-R82.

25. Pelosi P, Solca M, Ravagnan I, Tubiolo D, Ferrario L, Gattinoni L. Effects of heat and moisture exchangers on minute ventilation, ventilatory drive, and work of breathing during pressure-support ventilation in acute respiratory failure. Crit Care Med 1996;24(7):11841188.

26. Ploysongsang Y, Branson R, Rashkin MC, Hurst JM. Pressure flow characteristics of commonly used heat-moisture exchangers. Am Rev Respir Dis 1988;138(3):675-678.

27. Boyer A, Vargas F, Hilbert G, Gruson D, Mousset-Hovaere M, Castaing Y, et al. Small dead space heat and moisture exchangers do not impede gas exchange during noninvasive ventilation: a comparison with a heated humidifier. Intensive Care Med 2010;36(8):13481354.

28. Jaber S, Chanques G, Matecki S, Ramonatxo M, Souche B, Perrigault PF, et al. Comparison of the effects of heat and moisture exchangers and heated humidifiers on ventilation and gas exchange during non-invasive ventilation. Intensive Care Med 2002;28(11): 1590-1594

29. Lellouche F, Maggiore SM, Deye N, Taillé S, Pigeot J, Harf A, et al. Effect of the humidification device on the work of breathing during noninvasive ventilation. Intensive Care Med 2002;28(11):1582-1589.

30. Lellouche F, Pignatarro C, Maggiore SM, Deye N, Fischler M, Harf A, et al. Influence of the humidification device during non-invasive ventilation (abstract). Am J Respir Crit Care Med 2002;165(Suppl): A384.

31. Mehta S, Hill NS. Noninvasive ventilation. Am J Respir Crit Care Med 2001;163(2):540-577.

32. Lellouche F, Taillé S, Lefrancois F, Deye N, Maggiore SM, Jouvet $\mathrm{P}$, et al. Humidification performance of 48 passive airway humidifiers: comparison with manufacturer data. Chest 2009;135(2):276286.

33. Campbell RS, Davis K Jr, Johannigman JA, Branson RD. The effects of passive humidifier dead space on respiratory variables in paralyzed and spontaneously breathing patients. Respir Care 2000;45(3): 306-312.

34. Girault C, Breton L, Richard JC, Tamion F, Vandelet P, Aboab J, et al. Mechanical effects of airway humidification devices in difficult to wean patients. Crit Care Med 2003;31(5):1306-1311.

35. Iotti GA, Olivei MC, Palo A, Galbusera C, Veronesi R, Comelli A, et al. Unfavorable mechanical effects of heat and moisture exchangers in ventilated patients. Intensive Care Med 1997;23(4):399-405.

36. Le Bourdelles G, Mier L, Fiquet B, Djedaini K, Saumon G, Coste F, et al. Comparison of the effects of heat and moisture exchangers and heated humidifiers on ventilation and gas exchange during weaning trials from mechanical ventilation. Chest 1996;110(5):1294-1298. 


\section{Short-Term EfFects of Humidification Devices}

37. Pertusini E, Lellouche F, Catani F, Heili S, Taillé S, Rodriguez P, et al. Patient-ventilator asynchronies during NIV does level of pressure support matter? Intensive Care Med 2004;30(Suppl):S65.

38. Hinkson CR, Benson MS, Stephens LM, Deem S. The effects of apparatus dead space on $\mathrm{P}_{\mathrm{aCO} 2}$ in patients receiving lung-protective ventilation. Respir Care 2006;51(10):1140-1144.

39. Natalini G, Bardini P, Latronico N, Candiani A. Impact of heat and moisture exchangers on ventilatory pattern and respiratory mechanics in spontaneously breathing patients. Monaldi Arch Chest Dis 1994;49(6):561-564.

40. Prat G, Renault A, Tonnelier JM, Goetghebeur D, Oger E, Boles JM, et al. Influence of the humidification device during acute respiratory distress syndrome. Intensive Care Med 2003;29(12):2211-2215.

41. Prin S, Chergui K, Augarde R, Page B, Jardin F, Veillard-Baron A. Ability and safety of a heated humidifier to control hypercapnic acidosis in severe ARDS. Intensive Care Med 2002;28(12):1756-1760.
42. Richecoeur J, Lu Q, Vieira SR, Puybasset L, Kalfon P, Coriat P, et al. Expiratory washout versus optimization of mechanical ventilation during permissive hypercapnia in patients with severe acute respiratory distress syndrome. Am J Respir Crit Care Med 1999; 160(1):77-85.

43. Nunn JF, Campbell EJ, Peckett BW. Anatomical subdivisions of the volume of respiratory dead space and effect of position of the jaw. J Appl Physiol 1959;14(2):174-176.

44. Fraticelli AT, Lellouche F, L'Her E, Taillé S, Mancebo J, Brochard L. Physiological effects of different interfaces during noninvasive ventilation for acute respiratory failure. Crit Care Med 2009;37(3): 939-945.

45. Brochard L, Isabey D, Piquet J, Amaro P, Mancebo J, Messadi AA, et al. Reversal of acute exacerbations of chronic obstructive lung disease by inspiratory assistance with a face mask. N Engl J Med 1990;323(22):1523-1530. 